\title{
16 anos de competição eleitoral no litoral do Paraná (2000-2016): índices e resultados ${ }^{1}$
}

\author{
16 years of electoral competition in the Paraná coastal municipalities (2000-2016): \\ indexes and results
}

Márcio Cunha Carlomagno ${ }^{2}$

\begin{abstract}
Resumo
Analisamos os indicadores de competição política nos sete municípios do litoral do Paraná, entre 2000 e 2016, para traçar um panorama sobre as mudanças na representação política ocorridas no período. Assumimos e explicamos o argumento teórico de Aldrich \& Griffin (2007) de que maior competição eleitoral leva à maior responsividade do eleito para com os eleitores e, portanto, é um elemento importante para avaliar representação política. Para medir isso, utilizamos o índice de partidos efetivos de Laakso \& Taagepera (1979), aplicado aos candidatos. Descobrimos que no tocante ao executivo, em geral, as disputas tendem a ter entre 2 e 3 candidatos efetivos, replicando a dualidade de disputas presidenciais das duas últimas décadas, em consonância com os resultados apresentados por Peixoto \& Goulart (2014), em pesquisa de nível nacional. No legislativo, todos os municípios apresentam graus razoáveis de disputa eleitoral, o que indica que não há "cadeira garantida" para os mandatários - o que, pelo argumento dos incentivos racionais, leva os eleitos a prestarem mais atenção nos cidadãos, por medo da ameaça de serem trocados nas próprias eleições. Contudo, se destaca negativamente, no conjunto de municípios, a cidade de Guaraqueçaba, cujos índices de competição, tanto no legislativo quanto no executivo, apresentam queda constante no período analisado, o que pode levar ao comprometimento da representação política.
\end{abstract}

Palavras-chave: Eleições. Competição eleitoral. Representação política. Política local. Litoral do Paraná.

\begin{abstract}
We analyzed the indicators of political competition in the seven municipalities of the coast of Paraná, between 2000 and 2016, to outline the changes in political representation that occurred in the period. We assume and explain Aldrich \& Griffin's (2007) theoretical argument that greater electoral competition leads to greater responsiveness of the electto voters - and thus is an important element in assessing political representation. To measure this, we used the effective party index of Laakso \& Taagepera (1979), applied to candidates. We find that in the executive, in general, disputes tend to have between 2 and 3 effective candidates, replicating the duality of presidential disputes of the last two decades, in accordance with the results presented by Peixoto \& Goulart (2014) for the national level. In the legislative, all municipalities have reasonable degrees of electoral dispute, which indicates that there is no "guaranteed chair" for thein cumbents - which, through the argument of rational incentives, leads the electtopay more attention to citizens for fear of thet hreat to be changed

\footnotetext{
${ }^{1}$ Agradeço aos pareceristas anônimos da Revista Guaju pelos apontamentos e sugestões à versão preliminar deste texto. Os bancos de dados utilizados neste artigo estão disponíveis na conta deste autor no repositório Dataverse do Instituto de Ciências Sociais Quantitativas da Universidade de Harvard e pode ser acessado diretamente pelo link: http://dx.doi.org/10.7910/DVN/RQGE8T.

${ }^{2}$ Mestre e doutorando em Ciência Política pela Universidade Federal do Paraná. Bacharel em Gestão Pública pela UFPR Litoral. Contato: mccarlomagno@gmail.com
} 
in the next elections. However, the city of Guaraqueçaba stands out negatively in the set of municipalities, whose levels of competition, both in the legislature and in the executive branch, have declined steadily in the analyzed period, which can lead to the weakening of political representation. Keywords: Elections. Electoral competition. Political representation. Local politics. Coast of Paraná.

\section{Introdução}

Qual o cenário da representação política nos municípios do litoral do Paraná? Quais as mudanças nesse cenário nas últimas décadas? Podemos compreender que existe uma melhoria ou piora na representação política sendo realizada nesses municípios? Para se compreender as políticas públicas (o tipo, a qualidade, a quem se destinam, a quem favorecem ou prejudicam etc.) implementadas em um dado município é necessário compreender a representação política sendo realizada nessa localidade. Um dos elementos mais importantes para se compreender a representação política é a competição eleitoral. Este artigo analisa $16 \operatorname{anos}^{3}$ de competição eleitoral nos sete municípios do litoral do Paraná, entre 2000 e 2016.

A região do litoral paranaense tem sido objeto de estudo em ascensão em estudos recentes, tanto na área socioambiental (AZEVEDO, 2016; ESTADES, 2003; PIERRI et al., 2006) quanto em estudo de caso para algumas exemplares pesquisas na área da ciência política (HOROCHOVSKI et al., 2014).

O estudo sobre esta região específica justifica-se por três razões. Primeiro, segue uma prática já existente de pesquisas sobre a região, como o recém-citado estudo de Horochovski et al. (2014), em que os autores investigaram os sete municípios da região para ilustrar o potencial do método de análise de redes aplicada aos dados sobre financiamento eleitoral na região. Segundo, relacionado a isso, estudos de casos podem ser utilizados para ilustrar questões teóricas maiores, como por exemplo, resguardadas todas as devidas proporções da comparação, no clássico Who Governs?, em que Robert Dahl (2005), a partir do estudo de uma única cidade (New Haven, no estado de Connecticut), elaborou uma das mais importantes teorias políticas - senão a mais importante - do século XX. Terceiro, é uma contribuição ao conhecimento empírico sobre a região e sobre sua representação política.

Este artigo se organiza da seguinte maneira: na próxima seção apresentamos os fundamentos teóricos sobre a importância da competição política e resumimos como mensurar isso. $\mathrm{O}$ argumento teórico de Aldrich \& Griffin (2007) é que como políticos são motivados, essencialmente, pelo desejo

\footnotetext{
${ }^{3}$ Nossa análise começa no ano 2000, pois para a eleição de 1992 os dados são, atualmente, inexistentes no TSE, para todo o território nacional. Para a eleição de 1996, os dados do TSE estão apenas parcialmente completos; entre os estados com dados ausentes está o Paraná. Dessa forma, os dados disponíveis sobre a região iniciam em 2000.
} 
de conquistar e manter-se nos cargos, a ameaça real de perdê-los, nas eleições seguintes, faz com que, uma vez eleitos, sejam responsivos para com o eleitorado. Isto é, ouçam suas demandas e procurem atender as suas vontades manifestas. Medir o grau de competição eleitoral, portanto, é uma forma indireta (um proxy) de avaliar a representação política. Mas, para medir isso, não basta verificar o número absoluto de candidatos, visto que, no sistema eleitoral brasileiro, há uma parcela significativa de candidatos que não possui chances reais. Para verificar o grau verdadeiro da competição eleitoral utilizamos o índice de partidos efetivos, de Laakso \& Taagepera (1979), aplicado aos candidatos, conforme já realizado por outros estudos. A seguir, apresentamos os resultados. Nesse período, 4450 candidatos ${ }^{4}$ pleitearam os cargos de prefeito ou vereador. Os resultados gerais indicam que no tocante ao executivo, em geral, as disputas tendem a ter entre 2 e 3 candidatos efetivos, replicando a dualidade de disputas presidenciais das duas últimas décadas. Esses valores vão na mesma direção dos resultados apresentados por Peixoto \& Goulart (2014), em pesquisa sobre o nível municipal em todo o Brasil. No legislativo, todos os municípios apresentam graus razoáveis de disputa eleitoral, o que indica que não há "cadeira garantida" para os mandatários - o que, pelo argumento dos incentivos racionais, leva os eleitos a prestarem mais atenção nos cidadãos. Contudo, se destaca negativamente, no conjunto de municípios, a cidade de Guaraqueçaba, cujos índices de competição, tanto no legislativo quanto no executivo, apresentam queda constante no período analisado, o que pode levar ao comprometimento da representação política.

Por fim, resumimos os achados e sugerimos uma pequena agenda de pesquisa aos interessados na área.

\section{Representação política: qual a importância e como mensurar a competição eleitoral}

\section{Por que competição eleitoral?}

Por que estudar competição eleitoral? Por que a competição eleitoral é importante para o desenvolvimento da sociedade? Como isso se relaciona com o desenvolvimento sustentável, escopo da revista ao qual este artigo foi submetido? Ora, o desenvolvimento de uma sociedade está intimamente relacionado com a política praticada nessa comunidade, com a circulação de ideias. $\mathrm{O}$ desenvolvimento sustentável requer políticas públicas que o promovam, favoreçam, incentivem.

\footnotetext{
${ }^{4}$ Nossa unidade de análise são as candidaturas, não os candidatos como indivíduos. Ou seja, se um mesmo indivíduo se candidatou duas ou mais vezes no período, ele será contado como uma nova entrada a cada nova candidatura. Desse modo é possível - e provável - que o número de indivíduos candidatos seja razoavelmente menor do que esse número de candidaturas.
} 
Essas políticas públicas dependem da comunidade política de sua região. Os atores centrais, com poder efetivo de decisão, em qualquer comunidade política (embora evidentemente não os únicos) são os políticos eleitos. Logo, a implementação de políticas públicas para o desenvolvimento social depende de políticos que adotem tais ideias. A competição eleitoral é uma das formas de medir a qualidade dos políticos de uma sociedade, como veremos a seguir.

Aldrich \& Griffin (2007) argumentam que a competição eleitoral é a base de uma democracia real, que não seja democrática apenas nas aparências. Os autores explicam, de forma muito didática, a lógica de como competição política leva a melhores políticos e melhores práticas políticas. Vale a pena ler:

\begin{abstract}
A principal coisa que você precisa saber sobre partidos políticos é isso: um sistema partidário competitivo é necessário para a democracia efetiva. A ideia básica é simples. Competição eleitoral entre ou dentro de partidos políticos, em sua busca por vencer cargos políticos, leva os partidos, uma vez nos cargos, a respeitar as preocupações, necessidades e aspirações do público que os elegeu. Ou, também se pode dizer, leva políticos a responder às preocupações daqueles que podem retirá-los dos cargos na próxima oportunidade. Dessa forma, a existência de partidos políticos competitivos produz resultados políticos que visam dar benefícios a todos. Nenhum outro sistema político recompensa consistentemente as massas. A ausência de incentivos para recompensar todo o eleitorado ocorre não apenas para todos os sistemas não democráticos, mas também em sistemas supostamente democráticos nos quais não existe uma verdadeira concorrência para os cargos. Quando não há competição, os incentivos para que os ocupantes de cargos públicos recompensem os cidadãos diminuem. É o desejo pelos cargos - e, mais importante, o risco consistente de perder os cargos - que provê a motivação igualmente consistente para que as elites políticas prestem atenção no público. (ALDRICH; GRIFFIN, 2007, p. 2, tradução livre $)^{5}$.
\end{abstract}

Isto é, segundo Aldrich e Griffin, a competição política verdadeira leva os políticos a correrem o risco de perder seus cargos. Esse risco leva os políticos a prestarem atenção no eleitorado e procurem contemplar suas demandas. Se não houver o risco de perder eleições, não há incentivo racional para que políticos respondam aos cidadãos. Logo, a competição política leva a bons políticos.

\footnotetext{
${ }^{5}$ No original: "The one thing you need to know about political parties is just this: a competitive party system is necessary for effective democracy. This basic ideais rather simple. Competition between or among political parties in elections, which is to say, in their quest to win political office, leads the parties, once in office, to respect the concerns, needs, and aspirations of the public who elected them. Or, perhaps one might say it leads politicians to respond to the concerns of those who can toss them out of office the next time around. In this way, competitive political parties yield political out comes that seek to give benefits to all. No other political system can be counted on to reward the mass public consistently. An absence of incentives to reward the full electorate is not only true for all non democratic systems, but it is also true for put a tively democratic systems over which there is no genuine competition for office. When there is no competition, the incentive for office holders to reward the public lessens. It is the desire for office - and more importantly, the consistent risk of losing office - that provides the equally consistent motivation for political elites to pay attention to the public".
} 
Essa é uma visão intimamente associada com as proposições de Anthony Downs, que argumenta que todos os políticos são autointeressados. Para Downs (2013), as políticas públicas são uma função incidental de políticos perseguindo seus objetivos privados. Uma de suas mais famosas citações sentencia: “Os partidos formulam políticas públicas a fim de ganhar eleições, e não ganham eleições a fim de formular políticas públicas" (DOWNS, 2013, p. 50). A ideia apresentada também está, em certa medida, relacionada com a teoria do pluralismo político, que advoga que interesses diversos podem competir para ganhar a atenção do poder central (DAHL, 2005).

Ainda que não se concorde com os últimos autores (Downs, especialmente, tem sido alvo de grandes críticas nas últimas décadas, sobretudo por suas proposições sobre comportamento eleitoral), a ideia apresentada por Aldrich e Griffin de que maior competição eleitoral leva a políticos mais accountables (responsivos) às demandas dos cidadãos está bem estabelecida e aceita pela comunidade científica.

A competição eleitoral, no Brasil, é um tema em ascensão nos estudos nacionais, em especial pela relativamente recente acessibilidade a um universo imenso de dados, com estudos importantes, inclusive, sobre a esfera municipal (PEIXOTO; GOULART, 2014; PERES et al., 2010; CONCEIÇÃO, 2015).

Um excelente - e contrafactual - teste empírico da proposição teórica de Aldrich e Griffin foi a pesquisa conduzida por Pedro Cavalcante (2013). Querendo saber se, de fato, competição eleitoral gera governos mais eficientes, Cavalcante conduziu um teste, cruzando dados sobre competição eleitoral e indicadores de eficiência governamental em três áreas (educação, saúde e assistência social) para todos os municípios brasileiros. Segundo o autor, "Os resultados sugerem que a dimensão política explica parte do desempenho das prefeituras, apesar de a competição eleitoral não influenciar a eficiência governamental" (CAVALCANTE, 2013, p. 1569). Embora os resultados de Cavalcante não apresentem correlação entre eficiência governamental e os dados eleitorais, isso não reduz a relevância do pressuposto teórico ou sua força lógica.

A importância da compreensão de aspectos do campo político para analisar outputs relacionados à formulação de políticas públicas, especificamente em relação ao meio ambiente, pode ser ilustrada pela pesquisa de Horochovski et al. (2016), em que, analisando determinantes sociais do posicionamento dos deputados na votação do Código Florestal de 2012, conclui que "as características das bancadas importam nos processos decisórios relacionados à questão ambiental" (HOROCHOVSKI et al., 2016, p. 3). 


\section{Como medir isso?}

A literatura de ciência política apresenta muitos índices de competição eleitoral distintos (SANTOS, 2002). Uma das maneiras mais consolidadas de medir isso é, tal como realizado por Cavalcante (2013), a utilização do índice de partidos efetivos aplicado aos candidatos individuais. Também há vários desses índices disponíveis. Os mais célebres e utilizados são os de Laakso e Taagepera (1979) e Golosov (2010).

O índice de candidatos efetivos é importante por uma razão. O sistema eleitoral brasileiro incentiva os partidos a apresentarem muitos candidatos, até duas vezes o número de cadeiras em disputa $^{6}$. Então, em um município com o mínimo de nove vereadores, com 30 partidos, hipoteticamente pode haver até 540 candidatos para nove vagas. Esse valor extremo, evidentemente, não se efetiva na prática. Mas, ainda assim, há uma clara distinção entre os candidatos competitivos, com alguma chance de vitória, e os candidatos não competitivos. A existência de candidatos não competitivos pode ser explicada por uma longa lista de razões, que foge ao nosso escopo. Desde líderes de bairro sem chances reais, mas usados pelos partidos para atingir o quociente eleitoral, passando por militantes idealistas que não almejam ganhar, mas apenas levantar suas bandeiras, até candidatas de fachada usadas somente para preencher a cota de gênero a que os partidos são obrigados a obedecer, ou mesmo aqueles candidatos sérios, que até gostariam de ser competitivos, mas por distintas razões (como acesso a redes de financiamento de campanha) não conseguem se efetivar.

Dessa forma, a simples contagem geral do número de candidatos tem pouco a verdadeiramente nos responder, uma vez que poucos são "efetivos”, isto é, com alguma possibilidade mínima de se ganhar o cargo almejado. Por isso, é preciso separar os candidatos com alguma chance de se eleger daqueles sem chances. É isso que faz o índice de competição eleitoral, a partir do desempenho nas urnas dos candidatos, com sua votação. Cabe ressaltar que esta é uma verificação post hoc. Ou seja, somente depois da votação é possível identificar quais candidatos foram ou não competitivos, não sendo possível a aplicação desse índice antes das eleições.

Uma ressalva é a natureza proporcional da eleição brasileira. No nosso sistema eleitoral, os disputantes de cargos legislativos se elegem de forma proporcional, dependendo da votação do partido e/ou coligação. Em tese, mesmo um candidato não competitivo pode acabar sendo eleito, beneficiado pelo quociente da votação de seu partido ou coligação. Apesar disso, pesquisa recente (CARLOMAGNO, 2016) apontou que são raros os casos em que os eleitos não tiveram uma votação

\footnotetext{
${ }^{6}$ Conforme Lei ${ }^{\circ}$ 9.504/1997 e Lei n ${ }^{0} 13.165 / 2015$. Esse elemento tem sido alterado constantemente ao passar dos anos. Como não se trata de parte substancial de nossa análise, mas mera contextualização, acreditamos ser desnecessário nos prolongar nos detalhes históricos dessa questão.
} 
substantiva, como candidato competitivo. Dessa forma, podemos aplicar esse índice com relativa tranquilidade, mesmo se tratando de um sistema eleitoral proporcional.

O cálculo utilizado para se chegar ao índice que será utilizado pode ser resumido pela fórmula a seguir:

$$
N=\frac{1}{\sum_{i=1}^{n} P i^{2}}
$$

FONTE: LAAKSO; TAAGEPERA (1979).

Em que $\mathrm{Pi}^{2}$ é o quadrado da proporção de votos de um candidato $i$. Ou seja, para se obter o índice, encontra-se a proporção da votação de cada candidato (votação individual / total de votos para candidatos àquele cargo) e eleva-se ao quadrado. Na sequência, somam-se os resultados de todos os candidatos. Por fim, divide-se 1 pelo valor da soma obtida na etapa anterior. ${ }^{7}$

\section{Resultados}

Para começar, vamos apresentar o panorama geral do número de candidatos. Em todo esse período, foram 4450 candidaturas $^{8}$, a ambos os cargos, nos sete municípios da região. O que se contabilizou foram candidaturas, não indivíduos. Se um mesmo indivíduo candidatou-se em todas as eleições, ele é contado diferentemente em cada uma dessas ocasiões, de modo que entre as 4450 candidaturas existentes no período, o número de indivíduos únicos é potencialmente menor 9 .

O gráfico a seguir apresenta a distribuição por ano e município, para prefeito e vereador. Os detalhes dos valores únicos, para cada ano e município, assim como também do índice que será apresentado adiante, estão na Tabela 1, nos anexos.

\footnotetext{
7 Alternativamente, também calculamos os valores pelo índice de Golosov (2010). Essa é uma fórmula alternativa, utilizada por alguns autores. Nesse banco de dados, ela tendeu a diminuir valores baixos e aumentar valores mais altos. Isto é, intensifica as disparidades. A correlação entre os dois índices é quase perfeita, com R de Pearson de .978. Isto é, ambos índices apontam na mesma direção, embora com valores diferentes. Optamos por utilizar neste artigo apenas o índice mais tradicional, de Laakso e Taagepera.

${ }^{8}$ Foram retirados do banco de dados 140 candidatos que constavam com zero voto. Além do fato de, em termos lógicos, esses candidatos não poderem ser considerados "reais" (já que não receberam sequer seus próprios votos), o índice utilizado requer, para que a equação funcione, que somente candidatos com no mínimo 1 voto sejam considerados.

${ }^{9}$ Informações adicionais sobre esse fenômeno encontram-se nas Tabelas 2 e 3, nos anexos. Esse cruzamento só pode ser realizado a partir de 2004, pois os dados para 2000 não contêm informações necessárias para identificar os indivíduos únicos. Entre 2004 e 2016 foram 3795 candidaturas a algum cargo. Destas, 2831 foram candidaturas únicas e 964 (25,4\%) "recandidaturas".
} 

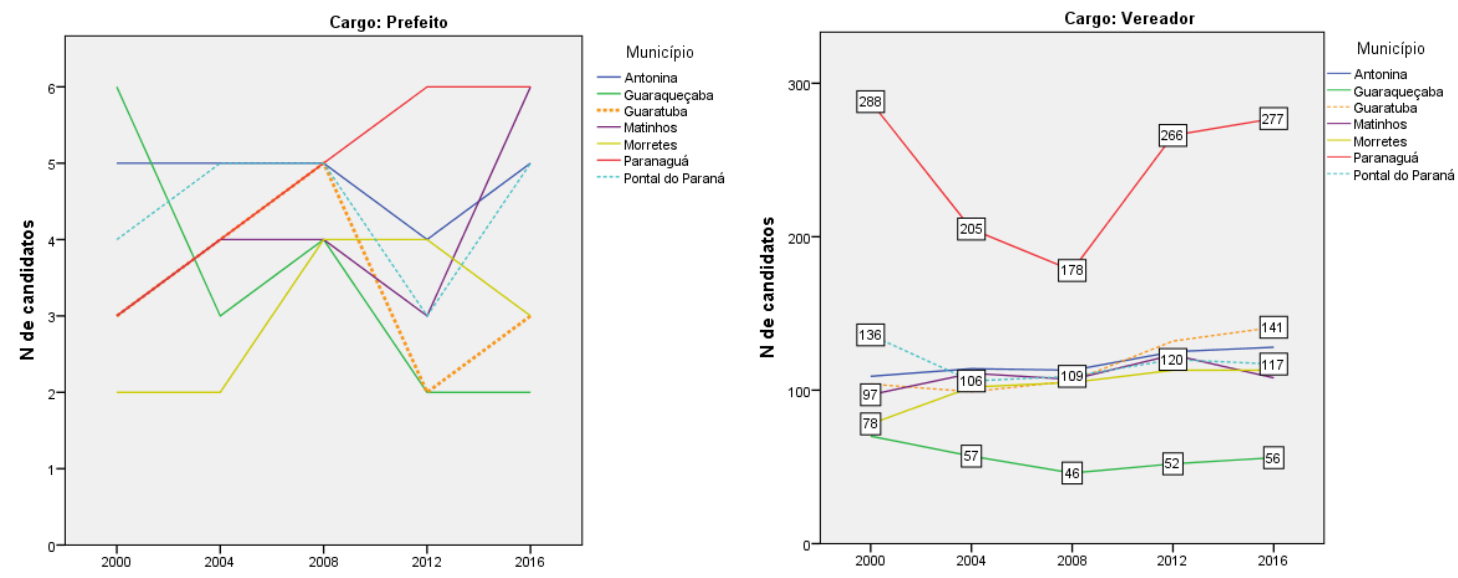

\section{GRÁFICO 1 - NÚMERO ABSOLUTO DE CANDIDATOS}

FONTE: Elaborado pelo autor. Dados brutos do Tribunal Superior Eleitoral.

A variação do número de candidatos a prefeito oscila bastante de ano a ano. Vale notar duas tendências, sem sentido contrário. No período, no município de Paranaguá apenas cresceu o número de candidatos, enquanto em Guaraqueçaba a tendência foi de redução da competição ao longo desse período.

Mas os valores mais instigantes, nesse caso, são os do legislativo. A primeira coisa a notar é que há três categorias de competição. No primeiro patamar, durante todo o período o município que mais teve candidatos foi Paranaguá. Entretanto, apresenta uma oscilação, com queda na concorrência entre 2000 e 2008, com crescimento em 2012 e estabilização em 2016. No entanto, mesmo em 2016 o número absoluto de candidatos continua abaixo do patamar de 2000.

No patamar mais baixo de competição está o município de Guaraqueçaba, que também apresentou queda na competição entre 2000 e 2008. Todos os demais municípios estão no mesmo nível, intermediário, relativamente estáveis ao longo do período, com oscilações para baixo de Pontal do Paraná e para cima de Guaratuba.

No entanto, como essas cidades possuem tamanhos distintos de eleitorado, a seguir vamos verificar o número de eleitores por candidato ${ }^{10}$, de modo que possamos comparar os municípios de forma mais direta. Nesse caso, a conta não possui muita lógica para os cargos majoritários, de modo que somente serão apresentados dados para os cargos legislativos.

Cabe se atentar que, aqui, a lógica dos valores é inversa à apresentada no gráfico anterior. Ou seja, quanto mais baixo o valor, maior oferta de candidatos em relação ao tamanho da população. Um

\footnotetext{
${ }^{10}$ É a simples razão entre número de eleitores e número de candidatos.
} 
hipotético valor "1" - que não é possível ser atingido, na prática, no sistema eleitoral brasileiro, dado o número existente de partidos e o limite de candidatos que cada partido pode lançar - indicaria que para cada eleitor há um candidato.

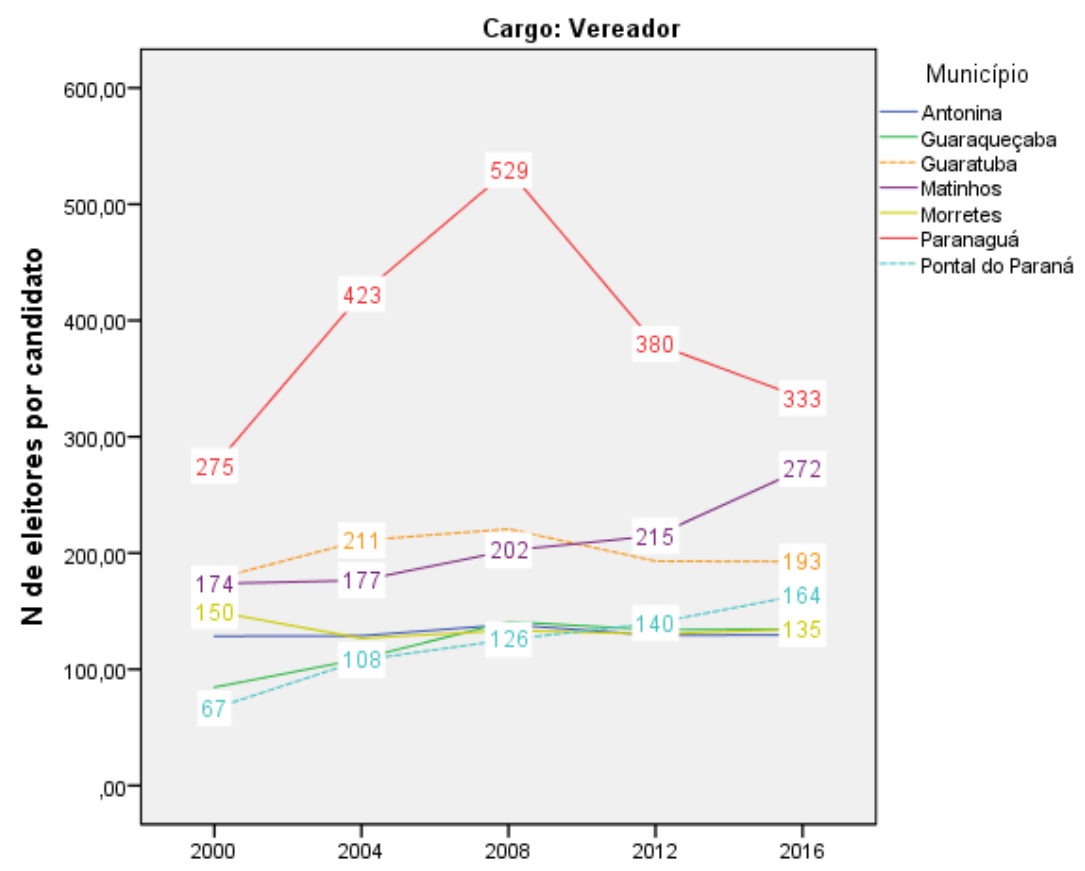

GRÁFICO 2 - NÚMERO DE ELEITORES POR CANDIDATO (VEREADOR)

FONTE: Elaborado pelo autor. Dados brutos do Tribunal Superior Eleitoral.

Podemos notar, como já indicamos, que as direções são opostas às do Gráfico 1. Ou seja, enquanto no Gráfico 1, por exemplo, em Paranaguá em 2008 o número de candidatos cai, no gráfico 2, logicamente, o número de eleitores por candidato sobe.

Percebemos que enquanto no Gráfico 1 Guaraqueçaba apresenta valores distantes dos demais municípios, quando ponderamos por número de eleitores no Gráfico 2 esse município está no mesmo patamar dos demais municípios, como Morretes e Antonina. Também percebemos que, com exceção de Paranaguá (o maior município da região), os demais estão em patamares similares, possibilitando uma comparação direta sem maiores problemas.

Os dados apresentados até aqui, contudo, são a título introdutório. A seguir, vamos apresentar os valores do índice de candidatos efetivos, com o índice de Laakso e Taagepera, cujo cálculo já explicamos na seção anterior. Esse é o principal indicador de competição eleitoral que iremos utilizar. Para quem queira verificar os valores únicos, também esses resultados constam na Tabela 1, nos anexos. 

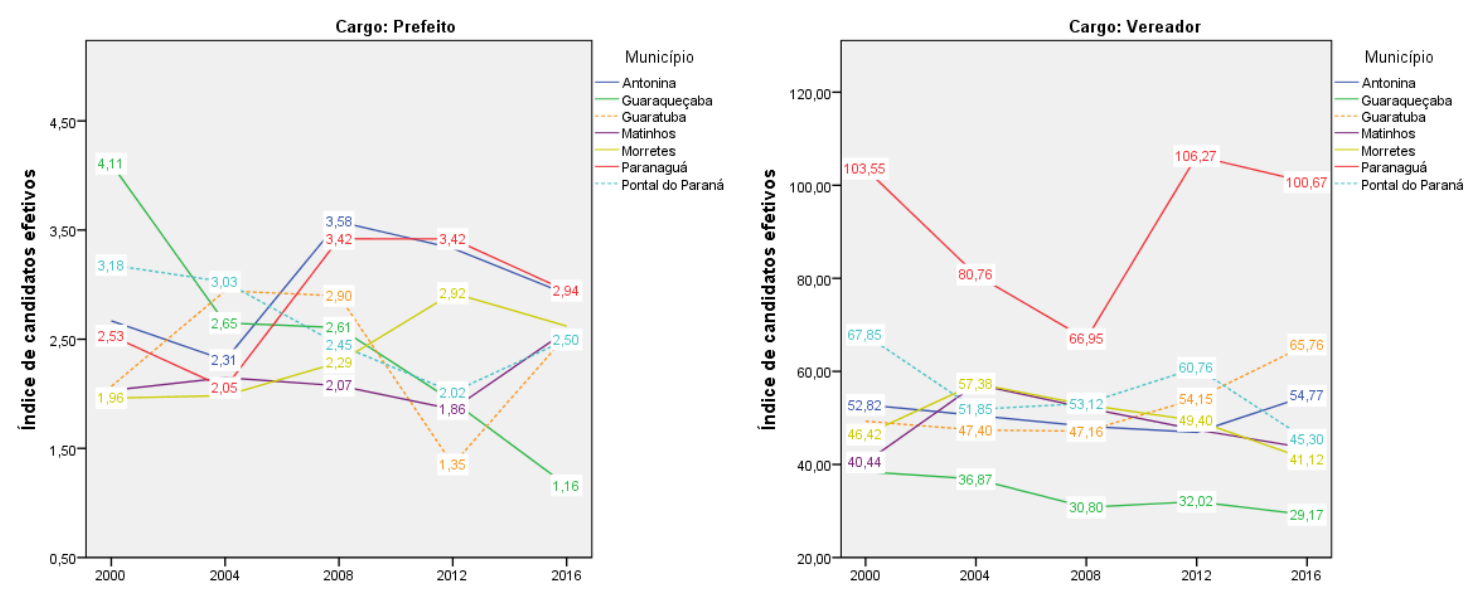

GRÁFICO 3 - NÚMERO DE CANDIDATOS EFETIVOS

FONTE: Elaborado pelo autor. Dados brutos do Tribunal Superior Eleitoral.

No caso do legislativo, em certa medida, os valores acompanham as mesmas tendências dos números absolutos de candidatos que vimos antes. Notamos a queda da competição em Paranaguá entre 2000 e 2008, com crescimento em 2012, só que, diferente dos números absolutos, retornando em um patamar acima do que havia em 2000.

Em relação aos anos mais recentes, Guaratuba, em destaque, e Antonina foram os municípios com maior crescimento da competição eleitoral, enquanto Pontal do Paraná, Matinhos e Morretes apresentam queda.

Em geral, podemos ressaltar que, em todos os casos, os municípios apresentam um nível razoável de competição. Considerando que a menor magnitude é de 9 cadeiras, mesmo o menor valor encontrado de candidatos efetivos (29,1 em Guaraqueçaba em 2016) pode ser considerado suficiente para garantir uma competição mínima.

Contudo, em alguns casos a tendência é preocupante. Paranaguá, Matinhos, Morretes e Antonina têm em 2016 patamares de competição eleitoral similares aos que tinham em 2000. Apenas Guaratuba teve crescimento da competição eleitoral no período - e apenas em 2016, pois até 2012 o patamar continuava o mesmo de 2000. Ou seja, é possível que tal pico seja devido a algum episódio da conjuntura local. Os casos mais preocupantes são de Pontal de Paraná e Guaraqueçaba, em que houve acentuada queda - especialmente o último município, cuja queda tem sido gradual e constante.

Por enquanto, os níveis de competição eleitoral ainda são suficientes para produzir políticos minimamente responsivos para com seu eleitorado, mas se essa tendência de diminuição da competição continuar, pode chegar o momento que os incentivos para a prática democrática sejam prejudicados. 
Já para a disputa de prefeitos, podemos identificar que durante quase todo período, Antonina e Paranaguá foram os municípios com maior competição para o executivo municipal, chegando a quase 3 candidatos efetivos ao cargo.

Quase todos os municípios apresentam padrões oscilantes, isto é, a competição sobe em alguns anos e diminui em outros, o que indica que fatores conjunturais são os maiores responsáveis por determinar o grau de competição eleitoral.

A exceção a esse padrão oscilante é, novamente, o município de Guaraqueçaba, para os qual os dados indicam um claro padrão decrescente, passando do município com maior competição, em 2000 (4,1 candidatos efetivos) ao, de longe, menos competitivo em 2016 (com apenas 1,1 candidato realmente efetivo). Nesse município, os incentivos racionais-eleitorais para que os governantes sejam responsivos para com o eleitorado parecem, à luz dos dados também sobre o legislativo, estar gravemente comprometidos.

No padrão geral do assim chamado "sistema" de partidos desses municípios podemos notar que as disputas variam, em média, entre 2 até 3 candidatos efetivos, assim reproduzindo, em nível local, a lógica de competição bipartidária ou tripartidária que é notória por caracterizar as disputas presidenciais desde 1994. Ocorre, portanto, também nesses municípios aquilo que Peixoto e Goulart (2014) já haviam descoberto como padrão nacional dos municípios brasileiros: a reprodução da lógica bipartidária no plano local.

\section{Considerações finais}

Neste texto, analisamos os indicadores de competição política nos sete municípios do litoral do Paraná, entre 2000 e 2016. Dessa forma, pudemos traçar um panorama sobre as mudanças na representação política ocorridas na última década e meia nessa região.

Nos resultados, percebemos que no tocante ao executivo, as disputas oscilam de ano para ano, o que indica a influência de fatores conjunturais, mas, em geral, tendem a ter entre 2 e 3 candidatos efetivos, replicando, de certa forma, a dualidade de disputas presidenciais das duas últimas décadas - o que está em consonância com o que Peixoto e Goulart (2014) já haviam descoberto.

No legislativo, todos os municípios apresentam graus razoáveis de disputa eleitoral, indicando que não há "cadeira garantida" para os mandatários - o que, pelo argumento dos incentivos racionais, leva os eleitos a prestarem mais atenção nos cidadãos, por medo da ameaça de serem trocados nas próprias eleições. 
Destaca-se negativamente, no entanto, no conjunto de municípios, a cidade de Guaraqueçaba, cujos índices de competição, tanto no legislativo quanto, especialmente, no executivo, apresentam queda constante no período analisado, o que pode levar ao enfraquecimento da representação política nessa localidade.

No plano teórico, este artigo apresentou uma compilação de argumentos em prol da importância do elemento competição eleitoral como um proxy (um indicador indireto) para analisar a representação política - ou, mais especificamente, os incentivos racionais para que eleitos sejam responsivos para com seu eleitorado. Também resumimos o modo como calcular o índice de partidos/candidatos efetivos, de modo que isso possibilita a reprodução deste estudo em outros contextos.

Este artigo, de forma alguma, esgota as questões relacionadas à representação política existente na região. Ao contrário, é tão somente um passo inicial. Entre tantas outras perguntas de pesquisa pertinentes, seria promissor averiguar a renovação efetiva dessa concorrência política. Devido ao modo como operacionalizamos nosso banco de dados, para os objetivos deste artigo o que se contabilizou foram candidaturas, não indivíduos. Isto é, se um mesmo indivíduo se candidatou em todas as eleições, ele é contado diferentemente em cada uma dessas ocasiões, de modo que entre as 4450 candidaturas existentes no período, o número de indivíduos únicos é potencialmente menor. Operacionalizar um banco de dados tendo os indivíduos como unidade de análise, de modo similar ao que Fernandes e Faganello (2016) fizeram para verificar a migração partidária, pode responder algumas questões importantes sobre a dominância - ou pluralismo - da elite local, na trilha daquilo que estudos de elites chamam de "circulação de elites" (PARETO, 1966). Esse esforço, contudo, está fora de nossos planos e resta, enquanto sugestão de agenda de pesquisa, aos futuros investigadores.

\section{Referências}

ALDRICH, J. H.; GRIFFIN, J. D. The one thing you need to know about political parties. Prepared for a conference in honor of Richard G. Niemi, held at the University of Rochester, November 3, 2007. Anais... 2007.

AZEVEDO, N. T. de. A vulnerabilidade social dos municípios do litoral do Paraná : construção do Índice de Vulnerabilidade Social (IVS) com base nos dados dos setores censitários IBGE 2010. Revista Guaju (Matinhos), v. 2, n. 2, p. 89-124, 2016.

BRASIL. Lei no 9.504/1997. Estabelece normas para as eleições.

BRASIL. Lei $\mathbf{n}^{\mathbf{0}} \mathbf{1 3 . 1 6 5 / 2 0 1 5}$. Altera as Leis 9.504/1997, 9.096/1995, e 4.737/1965, para reduzir os 
custos das campanhas eleitorais, simplificar a administração dos partidos políticos e incentivar a participação feminina.

CARLOMAGNO, M. C. Sistema proporcional, puxador de votos e um problema inexistente: os mais votados já são os que se elegem. Newsletter. Observatório de elites políticas e sociais do Brasil. NUSP/UFPR, v. 3, n. 10, p. 1-14, 2016.

CAVALCANTE, P. A competição eleitoral gera governos mais eficientes? Um estudo comparado das prefeituras no Brasil. Revista de Administração Pública, v. 47, n. 6, p. 1569-1592, 2013.

CONCEIÇÃO, B. da S. Sistema eleitoral e reeleição nas eleições municipais de 2012 para o executivo no Brasil. Revista Eletrônica de Ciência Política, v. 6, n. 1, p. 11-25, 3 ago. 2015.

DAHL, R. A. Who governs? democracy and power in an american city. 2. ed. New Haven: Yale University Press, 2005.

DOWNS, A. Uma teoria econômica da democracia. São Paulo: EDUSP, 2013.

ESTADES, N. P. O litoral do Paraná: entre a riqueza natural e a pobreza social. Desenvolvimento e Meio Ambiente, n. 8, p. 25-41, 2003.

FERNANDES, J. L. M.; FAGANELLO, M. A. Notas sobre a migração partidária nos municípios brasileiros. Newsletter. Observatório de elites políticas e sociais do Brasil. NUSP/UFPR, v. 3, n. 7, p. 1-15, 2016.

GOlOSOV, G. V. The effective number of parties: a new approach. Party Politics, v. 16, n. 2, p. 171-192, 2010.

HOROCHOVSKI, R. R. et al. Redes de Financiamento eleitoral nas eleições de 2008 no litoral do Paraná. Paraná Eleitoral, v. 3, n. 1, p. 103-131, 2014.

HOROCHOVSKI, R. R. et al. As mudanças no Código Florestal Brasileiro: uma análise de gênero, ideologia partidária e financiamento de campanha das bancadas parlamentares. Revista Guaju, v. 2, n. 2, p. 3-25, 2016.

LAAKSO, M.; TAAGEPERA, R. "Effective" number of parties: a measure with application to west Europe. Comparative Political Studies, v. 12, n. 3, p. 3-27, 1979.

PARETO, V. As elites e o uso da força na sociedade. In: SOUZA, A. de (Ed.). Sociologia política. Rio de Janeiro: Zahar, 1966.

PEIXOTO, V.; GOULART, N. Evolução da competição eleitoral municipal no Brasil (1996 a 2012). Teoria e Pesquisa: Revista de Ciência Política, v. 23, n. 2, p. 41-63, 2014.

PERES, G. et al. Competição política e sistema eleitoral brasileiro: algumas evidências empíricas. VIII Encontro da Associação Brasileira de Ciência Política (ABCP). Anais... 2010.

PIERRI, N. et al. A ocupação e o uso do solo no litoral paranaense: condicionantes, conflitos e tendências. Desenvolvimento e Meio Ambiente, n. 13, p. 137-167, 2006. 
SANTOS, W. G. dos. Votos e partidos. Almanaque de dados eleitorais: Brasil e outros países. Rio de Janeiro: FGV, 2002.

TRIBUNAL SUPERIOR ELEITORAL. Candidatos a prefeito e vereador: anos de 2000, 2004, 2008, 2012 e 2016. Banco de dados.

Artigo recebido em 28/03/2017. Aceito para publicação em 22/08/2017. 


\section{ANEXOS}

TABELA 1 - NÚMERO DE CANDIDATOS E ÍNDICES, POR MUNICÍPIO E ANO

\begin{tabular}{|c|c|c|c|c|c|c|c|c|c|c|c|}
\hline & \multicolumn{2}{|r|}{2000} & \multicolumn{2}{|r|}{2004} & \multicolumn{2}{|r|}{2008} & \multicolumn{2}{|r|}{2012} & \multicolumn{2}{|r|}{2016} \\
\hline & & $\mathrm{N}$ & $\begin{array}{c}\text { Índice de } \\
\text { candidatos } \\
\text { efetivos }\end{array}$ & $\mathrm{N}$ & $\begin{array}{l}\text { Índice de } \\
\text { candidatos } \\
\text { efetivos }\end{array}$ & $\mathrm{N}$ & $\begin{array}{l}\text { Índice de } \\
\text { candidatos } \\
\text { efetivos }\end{array}$ & $\mathrm{N}$ & $\begin{array}{c}\text { Índice de } \\
\text { candidatos } \\
\text { efetivos }\end{array}$ & $\mathrm{N}$ & $\begin{array}{c}\text { Índice de } \\
\text { candidatos } \\
\text { efetivos }\end{array}$ \\
\hline \multirow{2}{*}{ Antonina } & Prefeito & 5 & 2,67 & 5 & 2,31 & 5 & 3,58 & 4 & 3,33 & 5 & 2,91 \\
\hline & Vereador & 109 & 52,82 & 114 & 50,53 & 113 & 48,20 & 125 & 46,91 & 128 & 54,77 \\
\hline \multirow{2}{*}{ Guaraqueçaba } & Prefeito & 6 & 4,11 & 3 & 2,65 & 4 & 2,61 & 2 & 1,93 & 2 & 1,16 \\
\hline & Vereador & 70 & 38,43 & 57 & 36,87 & 46 & 30,80 & 52 & 32,02 & 56 & 29,17 \\
\hline \multirow{2}{*}{ Guaratuba } & Prefeito & 3 & 2,07 & 4 & 2,94 & 5 & 2,90 & 2 & 1,35 & 3 & 2,54 \\
\hline & Vereador & 104 & 49,28 & 99 & 47,40 & 106 & 47,16 & 132 & 54,15 & 141 & 65,76 \\
\hline \multirow{2}{*}{ Matinhos } & Prefeito & 3 & 2,03 & 4 & 2,15 & 4 & 2,07 & 3 & 1,86 & 6 & 2,58 \\
\hline & Vereador & 97 & 40,44 & 111 & 57,24 & 107 & 52,15 & 123 & 47,46 & 108 & 43,48 \\
\hline \multirow{2}{*}{ Morretes } & Prefeito & 2 & 1,96 & 2 & 1,98 & 4 & 2,29 & 4 & 2,92 & 3 & 2,62 \\
\hline & Vereador & 78 & 46,42 & 102 & 57,38 & 105 & 52,82 & 113 & 49,40 & 113 & 41,12 \\
\hline \multirow{2}{*}{ Paranaguá } & Prefeito & 3 & 2,53 & 4 & 2,05 & 5 & 3,42 & 6 & 3,42 & 6 & 2,94 \\
\hline & Vereador & 288 & 103,55 & 205 & 80,76 & 178 & 66,95 & 266 & 106,27 & 277 & 100,67 \\
\hline \multirow{2}{*}{$\begin{array}{l}\text { Pontal do } \\
\text { Paraná }\end{array}$} & Prefeito & 4 & 3,18 & 5 & 3,03 & 5 & 2,45 & 3 & 2,02 & 5 & 2,50 \\
\hline & Vereador & 136 & 67,85 & 106 & 51,85 & 109 & 53,12 & 120 & 60,76 & 117 & 45,30 \\
\hline
\end{tabular}

FONTE: O autor (2017).

NOTA: Dados do Tribunal Superior Eleitoral.

TABELA 2 - NÚMERO DE CANDIDATURAS ÚNICAS

\begin{tabular}{|c|c|c|c|c|}
\hline & & Recandidaturas & $\begin{array}{l}\text { Candidatura } \\
\text { única }\end{array}$ & Total \\
\hline \multirow{8}{*}{ 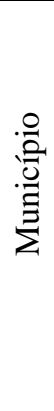 } & Antonina & 144 & 392 & 536 \\
\hline & Guaraqueçaba & 80 & 183 & 263 \\
\hline & Guaratuba & 133 & 388 & 521 \\
\hline & Matinhos & 120 & 382 & 502 \\
\hline & Morretes & 134 & 330 & 464 \\
\hline & Paranaguá & 230 & 774 & 1004 \\
\hline & Pontal do Paraná & 123 & 382 & 505 \\
\hline & Total & 964 & 2831 & 3795 \\
\hline
\end{tabular}

FONTE: O autor (2017).

NOTA: Dados brutos do Tribunal Superior Eleitoral. 
TABELA 3 - CRUZAMENTO ENTRE NÚMERO DE CANDIDATURAS E NÚMERO DE ELEIÇÕES

\begin{tabular}{|c|c|c|c|c|c|c|c|c|}
\hline & & & \multicolumn{5}{|c|}{$\mathbf{N}$ de vezes eleito } & \multirow[b]{2}{*}{ Total } \\
\hline & & & Zero & Uma & Duas & Três & Quatro & \\
\hline \multirow{8}{*}{ 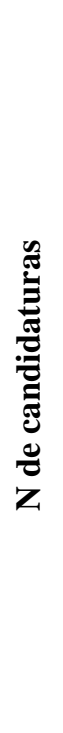 } & \multirow[b]{2}{*}{ Uma } & $\mathrm{N}$ & 2132 & 39 & 0 & 0 & 0 & 2171 \\
\hline & & $\begin{array}{c}\text { Resíduo } \\
\text { padronizado }\end{array}$ & 3,2 & $-7,9$ & $-6,1$ & $-3,3$ & $-2,5$ & \\
\hline & \multirow[b]{2}{*}{ Duas } & $\mathrm{N}$ & 356 & 57 & 15 & 0 & 0 & 428 \\
\hline & & $\begin{array}{c}\text { Resíduo } \\
\text { padronizado }\end{array}$ & $-1,8$ & 6,2 & 2,9 & $-1,5$ & $-1,1$ & \\
\hline & \multirow[b]{2}{*}{ Três } & $\mathrm{N}$ & 97 & 51 & 16 & 5 & 0 & 169 \\
\hline & & $\begin{array}{c}\text { Resíduo } \\
\text { padronizado }\end{array}$ & $-4,6$ & 12,9 & 7,8 & 4,6 &,- 7 & \\
\hline & \multirow[b]{2}{*}{ Quatro } & $\mathrm{N}$ & 14 & 22 & 17 & 9 & 8 & 70 \\
\hline & & $\begin{array}{c}\text { Resíduo } \\
\text { padronizado }\end{array}$ & $-6,3$ & 8,7 & 14,5 & 14,7 & 17,6 & \\
\hline & Total & $\mathrm{N}$ & 2599 & 169 & 48 & 14 & 8 & 2838 \\
\hline
\end{tabular}

FONTE: O autor (2017).

NOTA: Dados brutos do Tribunal Superior Eleitoral. 